\title{
Baculovirus as a vaccine vector
}

Hsin-Yu Lu, Yi-Hsuan Chen' and Hung-Jen Liu',2,*

'Institute of Molecular Biology; National Chung Hsing University; Taichung, Taiwan; ${ }^{2}$ Agricultural Biotechnology Center; National Chung Hsing University; Taichung, Taiwan

Keywords: baculovirus, surface display vector, vaccine, VSVG, gp64

Baculovirus is extensively utilized as an excellent tool for production of recombinant protein in insect cells. Baculovirus infects insects in nature and is non-pathogenic to humans. In addition to insect cells, baculovirus is capable of transducing a broad range of animal cells. Due to its biosafety, large cloning capacity, low cytotoxicity and non-replication nature in the transduced cells as well as the ease of manipulation and production, baculovirus has been utilized as RNA interference mediators, gene delivery vectors and vaccine vectors for a wide variety of applications. This article focuses on the utilization of baculoviruses as vaccine vectors to prepare antigen or subunit vaccines.

Baculoviruses are a diverse group of DNA viruses capable of infecting more than 600 insects, among which Autographa californica multiple nucleopolyhedrovirus (AcMNPV) is the best characterized and most extensively utilized. AcMNPV possesses a circular dsDNA genome of $134 \mathrm{~kb}$, replicates in a bi-phasic fashion, and produces two virion phenotypes during the infection cycle. ${ }^{1}$ The occlusion-derived virions (ODV), is adapted for survival in the environment and propagation of infection from animal to animal. Conversely, the other virion phenotype, the budded virions (BV), is adapted for propagation of infection from cell to cell throughout the animal, after infection is achieved by ODV in the midgut..$^{2-5} \mathrm{BV}$ efficiently enters many cell types in the infected animal. ${ }^{6-8}$ The infection cycle is completed when ODV are assembled and occluded within occlusion bodies in the nuclei of infected cells. Occlusion bodies are then released by cell lysis. AcMNPV has been developed as biological control agents and as protein expression vectors. The viral proteins $\mathrm{p} 10$ and polyhedrin are expressed abundantly in infected cells and are dispensable for virus replication, thus recombinant baculovirus can be constructed by placing the foreign gene under the control of p 10 or polyhedrin promoter, and utilized to infect insect cells for foreign gene expression. Baculovirus cloning capacity is as large as $38 \mathrm{~kb},{ }^{9}$ thus allowing for the insertion of multiple genes and regulatory elements. ${ }^{10,11}$ Baculovirus neither replicates inside the transduced cells nor integrates its DNA into host chromosomes in the absence of selective pressure, ${ }^{12,13}$ hence easing the safety concerns. The gp64 envelope glycoprotein of AcMNPV is an essential virion protein that is involved in

*Correspondence to: Hung-Jen Liu; Email: hjliu5257@nchu.edu.tw Submitted: 04/25/12; Revised: 05/01/12; Accepted: 05/08/12

http://dx.doi.org/10.4161/bioe.20679 both receptor binding and membrane fusion during viral entry into insect and mammalian cells. ${ }^{14}$ The gp64 envelope glycoprotein consists of a signal peptide (SS) and a mature domain that includes the transmembrane domain (TM) and cytoplasmic domain (CTD). ${ }^{15,16}$ After expression in insect cells, gp64 protein is transported to the plasma membrane, directed by the SS of gp64, where gp64 is displayed on the surface of infected cells as homotrimers. The gp64 CTD interacts with the budding nucleocapsids and directs the incorporation of gp64 into the virion. ${ }^{17}$ Accumulating evidences suggest that after entry, baculovirus can translocate into the nucleus through a complex cascade of steps and express baculoviral genes as well as the transgene. Baculoviruses triggers Toll-like receptor (TLR) 9- or TLR-3 dependent pathway for induction of innate immunity ${ }^{18,19}$ and interferes with the expression of a small percentage of host genes, particularly those pertaining to the innate immune responses.

Recombinant baculoviruses are attractive for high-level production of large eukaryotic proteins. Because of the flexibility of the AcNPV envelope, large DNA insertions can be accommodated in its genome. Compared with others, baculovirus expression system also exhibits abundant yields with proper glycosylation and other modifications pivotal to immunogenic potential. ${ }^{20}$ Thus, the baculovirus-insect cell expression system has been extensively utilized for the production of many recombinant proteins and commercial vaccines. ${ }^{21-32}$ The construction of recombinant baculovirus is performed in two steps. Foreign genes are first subcloned into a transfer vector propagated in E. coli and then inserted into the baculovirus genome by homologous recombination in insect cells producing recombinant progeny. ${ }^{33}$ This procedure was simplified considerably by the introduction of a shuttle bacmid propagated in E. coli containing the $\mathrm{Tn} 7$ attachment site from a transfer vector (Bac-to-Bac; Invitrogen) for transposition of foreign genes. ${ }^{34,35}$

\section{Baculovirus Surface Display by a gp64-Based Strategy}

The wild-type baculovirus triggers the innate immunity and potentiates the adaptive immune response, protecting the host from infection by several virus types. Baculovirus is used as a vector vaccine candidate, in which the antigens can be expressed by the vector within the host cells and displayed on the baculovirus surface or plasma membrane. Baculovirus surface display, using the TM and CTD of gp64, has been achieved by fusion with the gp64 gene of baculovirus, with expression driven by either the p10 or polyhedrin promoter. The significance of baculovirus 
gp64 in virus budding has been employed for the surface display of exogenous peptides by inserting a heterologous gene-encoding protein fused in-frame between the SS and TM of gp64. The fusion protein, after expression along with the native gp64, is translocated to the plasma membrane and incorporated into the baculoviral envelope. This surface display system has been extensively used to develop pseudotyped baculoviruses as a vaccine delivery platform. ${ }^{21-24,27,31,32,36,37}$

The CTD of a viral glycoprotein plays a critical role in protein incorporation, membrane fusion, virus budding and virus morphology. ${ }^{38-40}$ The function of CTDs may differ among different viruses. For example, both the native baculovirus gp64 and chimeric gp64 fused with the CTD from human respiratory syncytial virus (HRSV) fusion protein are efficiently incorporated into HRSV. ${ }^{41}$ In contrast, human immunodeficiency virus (HIV) envelope protein could not be incorporated into rabies virus or vesicular stomatitis virus unless the CTD of HIV envelope protein is replaced with that of the G protein of vesicular stomatitis virus (VSV). ${ }^{42,43} \mathrm{~A}$ compelling finding from our group has demonstrated that the origin of CTD greatly influences the properties and vaccine efficacy of HA-pseudotyped baculovirus. ${ }^{21}$ The differences in incorporation efficiencies may be due to the disparities in the palmitoylation in the CTD, a post-translational modification essential for targeting envelope proteins to lipid rafts, which are dynamic structures on cell surfaces and may act as selective concentration devices for proteins. ${ }^{44}$ Furthermore, recent studies have shown that the SS and CTD of gp64 can enhance the display of influenza HA on baculovirus surface, while the gp64 transmembrane domain impairs HA display. ${ }^{45}$ Collectively, these studies provide conclusive evidence that the origin of the CTD and TM exerts a profound effect on envelope protein incorporation, thereby influencing vaccine efficacy.

\section{Baculovirus Utilized as Antigen Display Vectors and Gene Delivery Vectors by a VSV G-based Strategy}

With the exception of the gp64-based display, expression of vesicular stomatitis virus (VSV) G protein, ${ }^{46,47}$ influenza virus neuraminidase, ${ }^{48}$ single chain antibody fragments, ${ }^{49}$ and Spodoptera exigua multiple nucleopolyhedrovirus $\mathrm{F}$ protein ${ }^{50}$ in insect cells also leads to incorporation of the protein into baculovirus envelope. Among these strategies, display of VSVG or heterologous proteins via the VSVG anchor seems to be the most widely adopted strategy, enhancing baculovirus transduction in vitro and in vivo. ${ }^{51-57}$ Wang and coworkers constructed a pseudotype baculovirus with the VSVG protein on the envelope; a construct which was used as a vector to construct recombinant baculovirus co-expressing GP5 and M protein of PRRSSV, under the transcriptional control of two independent cytomegalovirus immediate early enhancer/promoters. The resultant recombinant baculovirus efficiently expressed PRRSV GP5 and M protein in mammalian cells. Intramuscular injection of the recombinant baculoviruses induced the production of PRRSV-specific neutralizing antibodies and gamma interferon under dose-dependent pattern. ${ }^{58}$ Furthermore, baculovirus was also used as a novel and attractive gene delivery vehicle for mammalian cells.

\section{Baculovirus as a Bivalent Vaccine Vector}

A bicistronic transfer vector, pFastBacDUAL, which contains two promoters (polyhedrin and p10 viral promoters) and cloning sites in two separate cassettes for simultaneously subcloning two foreign genes for co-expression, was also applied. ${ }^{35}$

This approach has been used to simultaneously display two proteins on the viral envelope or plasma membrane. ${ }^{53,59}$ The baculovirus virions displaying two foreign proteins could be prepared as a bivalent vaccine. For example, immunization with baculovirus displaying the GP5 protein of respiratory syndrome virus (PRRSV) and the Cap protein of porcine circovirus type 2 (PCV2) on the viral envelope (via gp64 fusion) elicits high levels of anti-PRRSS GP5 and anti-PCV2 Cap neutralization antibodies and mediates cell immune response in swine. ${ }^{99}$ This dual surface display system can be utilized as an alternative strategy in order to develop bivalent vaccines against mixed virus infections. To allow rapid selection of recombinant baculoviruses, the co-expression of enhanced green fluorescent protein (EGFP) and one or multiple viral proteins has been previously described in reference 60. For example, the co-expression of EGFP and hemagglutinin (HA) gene of $\mathrm{H} 5 \mathrm{~N} 2$ avian influenza virus (AIV) in insect cells allows rapid identification of the recombinant baculoviruses in Sf-9 insect cells, eliminating cumbersome and time-consuming assays. The HA-encoding gene of AIV is expressed in host cells under the control of the polyhedrin promoter. The EGFP gene with cytomegalovirus (CMV) promoter is expressed under the control of the $P_{10}$ promoter. Furthermore, the co-expression of EGFP and one or two viral proteins were also established. The EGFP is expressed in host cells as an indicator for rapid identification of recombinant baculoviruses while viral proteins are displayed on the baculovirus envelope or plasma membrane. $22-24,27,31,32$ This system allows researchers to readily adjust the molar ratio of two expressed proteins. However, an inverse correlation may occur between amounts of two proteins because of two expressed genes competing with each other for protein synthesis within the cells.

\section{Polycistronic Vectors Carrying Multiple Expression Cassettes for Simultaneous Display and Expression of Multiple Proteins}

The multiprotein complexes uncovered in cells have increased the need for improved heterologous protein production in order to investigate their molecular structure and function. Genes driven by AcNPV late promoters are abundantly expressed, as well as authentically processed and targeted in insect cells. ${ }^{61}$ Expression of multiple genes in one cell can be completed by co-infection with numerous viruses, each carrying a single foreign gene. However, the logistical demand of maintaining several viruses at known titers and defined relative expression levels renders reproducible large-scale multi-protein production nearly impossible. Previous work has reported that construction of polycistronic vectors carrying multiple separate expression cassettes allows to simultaneous display or expression of multiple proteins..$^{59,61}$ Schematic illustration of polycistronic vectors carrying three 
or five expression cassettes is shown in Figure 1. Therefore, infection with one baculovirus expressing all heterologous genes greatly simplifies virus handling, resulting in reproducible expression and higher protein yield as compared to multiple single-gene viruses. ${ }^{62,63}$ Furthermore, a simple and versatile system, MultiBac, was established for generating recombinant baculovirus DNA to express numerous proteins or protein complexes consisting of many subunits. ${ }^{61}$ This system using transfer vectors that contain a multiplication module can be nested to facilitate assembly of polycistronic expression cassettes, thereby minimizing requirements for unique restriction sites.

\section{Outlook}

Baculovirus is an attractive and convenient tool for use as a vaccine expression/ delivery vector. Compared with other known viral vector, baculovirus has been extensively employed as antigen expression or display vectors for production of antigen or vaccines. In addition to the protein expression/display, baculovirus has emerged as a promising gene delivery vector for cancer gene therapy and regenerative medicine as well as an RNA interference mediator. We envisage that baculovirus will likely gain growing popularity as therapeutic vaccine and gene delivery vectors of the future.

\section{References}

1. Miller LK. The baculoviruses. (Plenum Press, New York NY) 1997.

2. Granados RR, Lawler KA. In vivo pathway of Autographa californica baculovirus invasion and infection. Virology 1981; 108:297-308; PMID:18635031. http://dx.doi.org/10.1016/0042-6822(81)90438-4.

3. Keddie BA, Aponte GW, Volkman LE. The pathway of infection of Autographa californica nuclear polyhedrosis virus in an insect host. Science 1989; 243:172830; PMID:2648574; http://dx.doi.org/10.1126/science. 2648574 .

4. Keddie BA, Volkman LE. Infectivity difference between the two phenotypes of Autographa californica nuclear polyhedrosis virus: importance of the $64 \mathrm{~K}$ envelope glycoprotein. J Gen Virol 1985; 66:1195-200; http:// dx.doi.org/10.1099/0022-1317-66-5-1195.

5. Monsma SA, Oomens AGP, Blissard GW. The GP64 envelope fusion protein is an essential baculovirus protein required for cell-to-cell transmission of infection. J Virol 1996; 70:4607-16; PMID:8676487.

6. Engelhard EK, Kam-Morgan LNW, Washburn JO, Volkman LE. The insect tracheal system: a conduit for the systemic spread of Autographa californica M nuclear polyhedrosis virus. Proc Natl Acad Sci USA 1994; 91:3224-7; PMID:8159729; http://dx.doi. org/10.1073/pnas.91.8.3224.

7. Federici BA. Baculovirus pathogenesis (L.K. Miller Plenum Press, New York NY) 1997; 33-60.
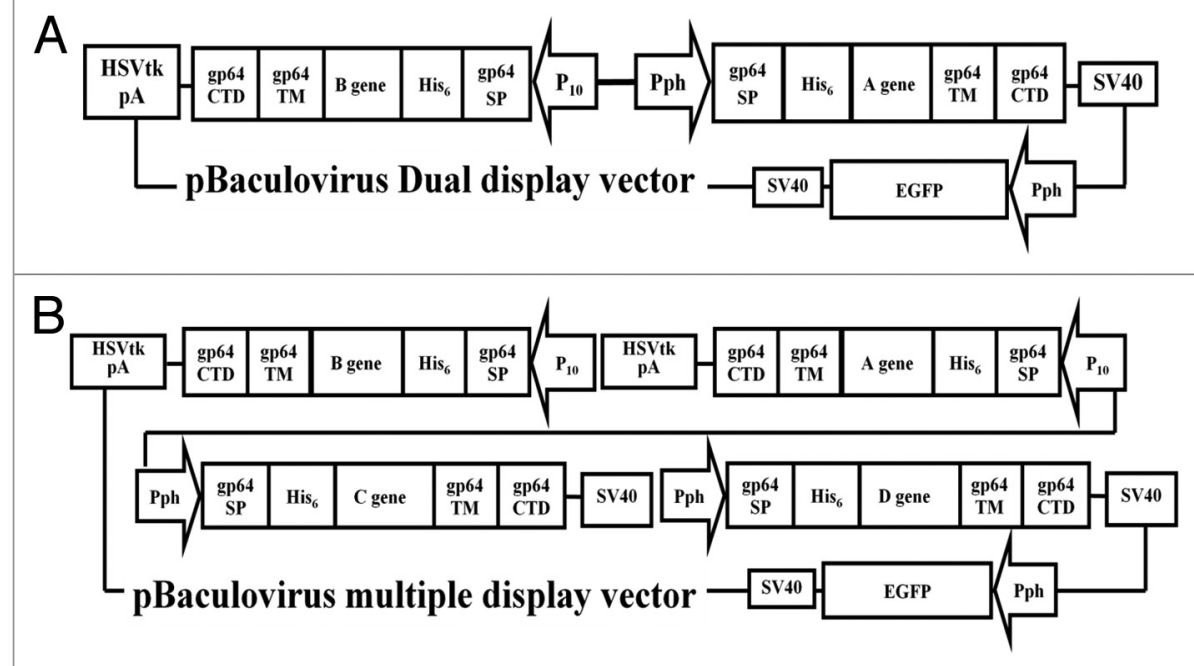

Figure 1. Schematic illustration of polycistronic vectors carrying multiple expression cassettes. The vectors carrying three (A) or five (B) expression cassettes are shown. The pBaculovirus Dual display vector contains three expression cassettes. The sequences coding for gp64 SS-His6-A target gene-gp64 TM-gp64 CTD and gp64 SS-His6-B target gene-gp64 TM-gp64 CTD, which can display two different proteins on viral envelop or plasma membrane under the control of baculovirus $\mathrm{p} 10$ and polyhedrin promoters. The pBaculovirus multiple display vector carries five expression cassettes as shown in the diagram. The target gene can be expressed under the control of the $P_{10}$ promoter or polyhedrin promoters while and EGFP gene with cytomegalovirus promoter is expressed under the control of the polyhedrin promoter. The EGFP is expressed in host cells for rapid identification of recombinant baculovirus while target proteins are displayed on the baculovirus envelope or plasma membrane.

\section{Acknowledgments}

This work was supported by the grants from Council of Agriculture (101AS-10.2.4-HI-H2 and 101AS-10.6.1-BQ-B6), National Science Council (NSC100-2324-B-005-009-CC1), and Ministry of Education, Taiwan, R.O.C. under the ATU plan.

8. Flipsen JTM, Martens JWM, van Oers MM, Vlak JM, van Lent JWM. Passage of Autographa californica nuclear polyhedrosis virus through the midgut epithelium of Spodoptera exigua larvae. Virology 1995; 208:32835; PMID:11831715; http://dx.doi.org/10.1006/ viro.1995.1156.

9. Cheshenko N, Krougliak N, Eisensmith RC, Krougliak VA. A novel system for the production of fully deleted adenovirus vectors that does not require helper adenovirus. Gene Ther 2001; 8:846-54; PMID:11423932; http://dx.doi.org/10.1038/sj.gt.3301459.

10. Kost TA, Condreay JP, Jarvis DL. Baculovirus as versatile vectors for protein expression in insect and mammalian cells. Nat Biotechnol 2005; 23:567-75; PMID:15877075; http://dx.doi.org/10.1038/nbt1095.

11. Kost TA, Condreay JP, Ames RS. Baculovirus gene delivery: a flexible assay development tool. Curr Gene Ther 2010; 10:168-73; PMID:20392201; http:// dx.doi.org/10.2174/156652310791321224.

12. Chen CY, Wu HH, Chen CP, Chern SR, Hwang SM, Huang SF, et al. Biosafety assessment of human mesenchymal stem cells engineered by hybrid baculovirus vectors. Mol Pharm 2011; 8:1505-14; PMID:21197956; http://dx.doi.org/10.1021/mp100368d.

13. Merrihew RV, Clay WC, Condreay JP, Witherspoon SM, Dallas WS, Kost TA. Chromosomal integration of transduced recombinant baculovirus DNA in mammalian cells. J Virol 2001; 75:903-9; PMID:11134303; http://dx.doi.org/10.1128/JVI.75.2.903-9.2001
14. Zhou J, Blissard GW. Identification of a GP64 subdomain involved in receptor binding by budded virions of the baculovirus Autographica californica multicapsid nucleopolyhedrovirus. J Virol 2008; 82:444960; PMID:18287233; http://dx.doi.org/10.1128/ JVI.02490-07.

15. Monsma SA, Oomens AG, Blissard GW. The GP64 envelope fusion protein is an essential baculovirus protein required for cell-to-cell transmission of infection. J Virol 1996; 70:4607-16; PMID:8676487.

16. Kitagawa $\mathrm{Y}$, Tani H, Limn CK, Matsunaga TM, Moriishi K, Matsuura Y. Ligand-directed gene targeting to mammalian cells by pseudotype baculoviruses. J Virol 2005; 79:3639-52; PMID:15731258; http:// dx.doi.org/10.1128/JVI.79.6.3639-52.2005.

17. Oomens AG, Blissard GW. Requirement for GP64 to drive efficient budding of Autographa californica multicapsid nucleopolyhedrovirus. Virology 1999; 254:297314; PMID:9986796; http://dx.doi.org/10.1006/ viro. 1998.9523

18. Chen GY, Shiah HC, Su HJ, Chen CY, Chuang YJ, Lo $\mathrm{WH}$, et al. Baculovirus transduction of mesenchymal stem cells triggers the toll-like receptor 3 pathway. J Virol 2009; 83:10548-56; PMID:19656899; http:// dx.doi.org/10.1128/JVI.01250-09.

19. Abe T, Hemmi H, Miyamoto H, Moriishi K, Tamura $\mathrm{S}$, Takaku H, et al. Involvement of the Toll-like receptor 9 signaling pathway in the induction of innate immunity by baculovirus. J Virol 2005; 79:284758; PMID:15709004; http://dx.doi.org/10.1128/ JVI.79.5.2847-58.2005. 
20. Hassan SS, Roy P. Expression and functional characterization of bluetongue virus VP2 protein: role in cell entry. J Virol 1999; 73:9832-42; PMID:10559295.

21. Yang DG, Chung YC, Lai YK, Lai CW, Liu HJ, $\mathrm{Hu}$ YC. Avian influenza virus hemagglutinin display on baculovirus envelope: cytoplasmic domain affects virus properties and vaccine potential. Mol Ther 2007; 15:989-96; PMID:17375072; http://dx.doi. org/10.1038/mt.sj.6300131.

22. Lin YH, Lee LH, Shih WL, Hu YC, Liu HJ. Baculovirus surface display of sigmaC and sigmaB proteins of avian reovirus and immunogenicity of the displayed proteins in a mouse model. Vaccine 2008; 26:63617; PMID:18809448; http://dx.doi.org/10.1016/j.vaccine.2008.09.008

23. Xu XG, Liu HJ. Baculovirus surface display of E2 envelope glycoprotein of classical swine fever virus and immunogenicity of the displayed proteins in a mouse model. Vaccine 2008; 26:5455-60; PMID:18708107; http://dx.doi.org/10.1016/j.vaccine.2008.07.090.

24. Xu XG, Chiou MT, Zhang YM, Tong DW, Hu JH, Zhang MT, et al. Baculovirus surface display of E(rns) envelope glycoprotein of classical swine fever virus. J Virol Methods 2008; 153:149-55; PMID:18727937; http://dx.doi.org/10.1016/j.jviromet.2008.07.019.

25. Syed Musthaq S, Madhan S, Sahul Hameed AS, Kwang J. Localization of VP28 on the baculovirus envelope and its immunogenicity against white spot syndrome virus in Penaeus monodon. Virology 2009; 391:31524; PMID:19604531; http://dx.doi.org/10.1016/j. virol.2009.06.017.

26. Wu QF, Fang LR, Wu XB, Li B, Luo R, Yu Z, et al. A pseudotype baculovirus-mediated vaccine confers protective immunity against lethal challenge with $\mathrm{H} 5 \mathrm{~N} 1$ avian influenza virus in mice and chickens. Mol Immunol 2009; 46:2210-7; PMID:19446339; http:// dx.doi.org/10.1016/j.molimm.2009.04.017.

27. Xu XG, Tong DW, Chiou MT, Hsieh YC, Shih WL, Chang CD, et al. Baculovirus surface display of NS3 nonstructural protein of classical swine fever virus. J Virol Methods 2009; 159:259-64; PMID:19406162; http://dx.doi.org/10.1016/j.jviromet.2009.04.013.

28. Yoshida S, Kawasaki M, Hariguchi N, Hirota K, Matsumoto M. A baculovirus dual expression systembased malaria vaccine induces strong protection against Plasmodium berghei sporozoite challenge in mice. Infect Immun 2009; 77:1782-9; PMID:19223476; http:// dx.doi.org/10.1128/IAI.01226-08.

29. Fang R, Feng H, Nie H, Wang L, Tu P, Song Q, et al. Construction and immunogenicity of pseudotype baculovirus expressing Toxoplasma gondii SAG1 protein in BALB/c mice model. Vaccine 2010; 28:1803-7; PMID:20018269; http://dx.doi.org/10.1016/j.vaccine.2009.12.005.

30. Lee HJ, Park N, Cho HJ, Yoon JK, Van ND, Oh YK, et al. Development of a novel viral DNA vaccine against human papillomavirus: AcHERV-HP16L1. Vaccine 2010; 28:1613-9; PMID:19961961; http://dx.doi. org/10.1016/j.vaccine.2009.11.044.

31. Xu XG, Tong DW, Wang ZS, Zhang Q, Li ZC, Zhang $\mathrm{K}$, et al. Baculovirus virions displaying infectious bursal disease virus VP2 protein protect chickens against infectious bursal disease virus infection. Avian Dis 2011; 55:223-9; PMID:21793437; http://dx.doi. org/10.1637/9597-111210-Reg.1.

32. Xu XG, Wang ZS, Zhang Q, Li ZC, Zhao HN, Li W, et al. Baculovirus surface display of $\mathrm{E}$ envelope glycoprotein of Japanese encephalitis virus and its immunogenicity of the displayed proteins in mouse and swine models. Vaccine 2011; 29:636-43; PMID:21115062; http://dx.doi.org/10.1016/j.vaccine.2010.11.045.

33. O'Reilly DR, Miller LK, Luckow VA. Baculovirus expression vectors. A laboratory manual. (Oxford University Press, New York 1994).

34. Luckow VA, Lee SC, Barry GF, Olins PO. Efficient generation of infectious recombinant baculoviruses by sitespecific transposon-mediated insertion of foreign genes into a baculovirus genome propagated in Escherichia coli. J Virol 1993; 67:4566-79; PMID:8392598.
35. Bac-to-Bac Baculoviorus Expression Systems Manual. (Invitrogen, Life Technologies Inc. 2000).

36. Jin R, Lv Z, Chen Q, Quan Y, Zhang H, Li S, et al. Safety and immunogenicity of $\mathrm{H} 5 \mathrm{~N} 1$ influenza vaccine based on baculovirus surface display system of Bombyx mori. PLoS One 2008; 3:3933; PMID:19079592; http://dx.doi.org/10.1371/journal.pone.0003933.

37. Mlambo G, Kumar N, Yoshida S. Functional immunogenicity of baculovirus expressing Pfs25, a human malaria transmission-blocking vaccine candidate antigen. Vaccine 2010; 28:7025-9; PMID:20709008; http://dx.doi.org/10.1016/j.vaccine.2010.08.022.

38. Schnell MJ, Buonocore L, Boritz E, Ghosh HP, Chernish R, Rose JK. Requirement for a non-specific glycoprotein cytoplasmic domain sequence to drive efficient budding of vesicular stomatitis virus. EMBO J 1998; 17:1289-96; PMID:9482726; http://dx.doi. org/10.1093/emboj/17.5.1289.

39. Takimoto T, Bousse T, Coronel EC, Scroggs RA, Portner A. Cytoplasmic domain of Sendai virus HN protein contains a specific sequence required for its incorporation into virions. J Virol 1998; 72:9747-54; PMID:9811709.

40. Yao Q, Compans RW. Differences in the role of the cytoplasmic domain of human parainfluenza virus fusion proteins. J Virol 1995; 69:7045-53; PMID:7474124.

41. Oomens AG, Wertz GW. The baculovirus GP64 protein mediates highly stable infectivity of a human respiratory syncytial virus lacking its homologous transmembrane glycoproteins. J Virol 2004; 78:12435; PMID:14671094; http://dx.doi.org/10.1128/ JVI.78.1.124-35.2004

42. Johnson JE, Schnell MJ, Buonocore L, Rose JK. Specific targeting to $\mathrm{CD}^{+}$cells of recombinant vesicular stomatitis viruses encoding human immunodeficiency virus envelope proteins. J Virol 1997; 71:50608; PMID:9188571.

43. Mebatsion T, Konig M, Conzelmann KK. Budding of rabies virus particles in the absence of the spike glycoprotein. Cell 1996; 84:941-51; PMID:8601317; http://dx.doi.org/10.1016/S0092-8674(00)81072-7.

44. Takeda M, Leser GP, Russell CJ, Lamb RA. Influenza virus hemagglutinin concentrates in lipid raft microdomains for efficient viral fusion. Proc Natl Acad Sci USA 2003; 100:14610-7; PMID:14561897; http://dx.doi. org/10.1073/pnas.2235620100

45. Tang XC, Lu HR, Ross TM. Hemagglutinin displayed baculovirus protects against highly pathogenic influenza. Vaccine 2010; 28:6821-31; PMID:20727393; http://dx.doi.org/10.1016/j.vaccine.2010.08.040.

46. Chapple SDJ, Jones IM. Non-polar distribution of green fluorescent protein on the surface of Autographa californica nucleopolyhedrovirus using a heterologous membrane anchor. J Biotechnol 2002; 95:269-75; PMID:12007867; http://dx.doi.org/10.1016/S0168 1656(02)00023-8.

47. Mäkelä AR, Oker-Blom C. Baculovirus display: a multifunctional technology for gene delivery and eukaryotic library development. Adv Virus Res 2006; 68:91112; PMID:16997010; http://dx.doi.org/10.1016/ S0065-3527(06)68003-2.

48. Borg J, Nevsten P, Wallenberg R, Stenstrom M, Cardell $S$, Falkenberg C, et al. Amino-terminal anchored surface display in insect cells and budded baculovirus using the amino-terminal end of neuraminidase. J Biotechnol 2004; 114:21-30; PMID:15464595; http:// dx.doi.org/10.1016/j.jbiotec.2004.05.014.

49. Kitidee K, Nangola S, Gonzalez G, Boulanger P, Tayapiwatana C, Hong SS. Baculovirus display of single chain antibody $(\mathrm{scFv})$ using a novel signal peptide. BMC Biotechnol 2010; 10:80; PMID:21092083; http://dx.doi.org/10.1186/1472-6750-10-80.

50. Yu IL, Lin YC, Robinson JH, Lung O. Transduction of vertebrate cells with Spodoptera exigua multiple nucleopolyhedrovirus F protein-pseudotyped gp64null Autographa californica multiple nucleopolyhedrovirus. J Gen Virol 2009; 90:2282-7; PMID:19474242; http://dx.doi.org/10.1099/vir.0.012138-0.
51. Tani H, Nishijima M, Ushijima $H$, Miyamura $T$, Matsuura Y. Characterization of cell-surface determinants important for baculovirus infection. Virology 2001; 279:343-53; PMID:11145915; http://dx.doi org/10.1006/viro.2000.0699.

52. Tani H, Limn CK, Yap CC, Onishi M, Nozaki M, Nishimune $Y$, et al. In vitro and in vivo gene delivery by recombinant baculoviruses. J Virol 2003; 77:9799 808; PMID:12941888; http://dx.doi.org/10.1128/ JVI.77.18.9799-808.2003

53. Facciabene A, Aurisicchio L, La Monica N. Baculovirus vectors elicit antigen-specific immune responses in mice. J Virol 2004; 78:8663-72; PMID:15280475; http://dx.doi.org/10.1128/JVI.78.16.8663-72.2004.

54. Kitagawa Y, Tani H, Limn CK, Matsunaga TM, Moriishi K, Matsuura Y. Ligand-directed gene targeting to mammalian cells by pseudotype baculoviruses. J Virol 2005; 79:3639-52; PMID:15731258; http:// dx.doi.org/10.1128/JVI.79.6.3639-52.2005.

55. Kaikkonen MU, Räty JK, Airenne KJ, Wirth T, Heikura T, Ylä-Herttuala S. Truncated vesicular stomatitis virus $G$ protein improves baculovirus transduction efficiency in vitro and in vivo. Gene The 2006; 13:304-12; PMID:16267571; http://dx.doi. org/10.1038/sj.gt.3302657.

56. Lu LQ, Ho YF, Kwang J. Suppression of porcine arterivirus replication by baculovirus-delivered shRNA targeting nucleoprotein. Biochem Biophys Res Commun 2006; 340:1178-83; PMID:16405916; http://dx.doi. org/10.1016/j.bbrc.2005.12.133

57. Zhou J, Blissard GW. Display of heterologous proteins on gp64null baculovirus virions and enhanced budding mediated by a vesicular stomatitis virus G-stem construct. J Virol 2008; 82:1368-77; PMID:17989172; http://dx.doi.org/10.1128/JVI.02007-07.

58. Wang S, Fang L, Fan H, Jiang Y, Pan Y, Luo R, et al. Construction and immunogenicity of pseudotype baculovirus expressing GP5 and M protein of porcine reproductive and respiratory syndrome virus. Vaccine 2007; 25:8220-7; PMID:17980465; http://dx.doi. org/10.1016/j.vaccine.2007.09.069.

59. Xu XG, Wang ZS, Zhang Q, Li ZC, Ding L, Li W, et al. Baculovirus as a PRRSV and PCV2 bivalent vaccine vector: baculovirus virions displaying simultaneously GP5 glycoprotein of PRRSV and capsid protein of PCV2. J Virol Methods 2012; 179:359-66; PMID:22172969; http://dx.doi.org/10.1016/j.jviromet.2011.11.023

60. Hu YC, Luo YL, Ji WT, Chulu JLC, Chang PC, Shieh $\mathrm{H}$, et al. Dual expression and analysis of the HA protein of $\mathrm{H} 5 \mathrm{~N} 2$ avian influenza virus in a baculovirus system. J Virol Methods 2006; 135:43-8; PMID:16530857; http://dx.doi.org/10.1016/j.jviromet.2006.01.023.

61. Berger I, Fitzgerald DJ, Richmond TJ. Baculovirus expression system for heterologous multiprotein complexes. Nat Biotechnol 2004; 22:1583-7; PMID:15568020; http://dx.doi.org/10.1038/nbt1036.

62. Roy P, Mikhailov M, Bishop DH. Baculovirus multigene expression vectors and their use for understanding the assembly process of architecturally complex virus particles. Gene 1997; 190:119-29; PMID:9185857; http://dx.doi.org/10.1016/S0378-1119(96)00619-1.

63. Bertolotti-Ciarlet A, Ciarlet M, Crawford SE, Conner ME, Estes MK. Immunogenicity and protective efficacy of rotavirus $2 / 6$-virus-like particles produced by a dual baculovirus expression vector and administered intramuscularly, intranasally, or orally to mice. Vaccine 2003; 21:3885-900; PMID:12922123; http://dx.doi. org/10.1016/S0264-410X(03)00308-6. 